\title{
Meta-Analysis of Association between Pathological Characteristics and Renal Outcomes in Adult Idiopathic Membranous Nephropathy
}

\section{Yizhi Chen, Guangyan Cai and Xiangmei Chen*}

State Key Laboratory of Kidney Disease, Department of Nephrology, Chinese PLA General Hospital, Beijing, P. R China

\section{Abstract}

Background and objectives: The associations of pathological features with renal outcomes in adult Idiopathic Membranous Nephropathy (IMN) are still controversial. A meta-analysis was performed to assess whether pathological features could independently predict risk of progressive kidney disease in adult IMN patients.

Methods: The PubMed database (January 2000 to September 2013) was searched to identify cohort studies of adult IMN patients ( $\geq 50$ patients for each study) in which at least one of the following pathological features was assessed: segmental sclerosis, tubular atrophy/interstitial fibrosis, arteriosclerosis, C3 deposits by immunofluorescence, and the stage or heterogeneity of electron dense deposits by electron microscopy. Renal outcomes included development of renal insufficiency or progression to ESRD.

Results: Nine cohort studies were included. A total of 2080 patients with 252 hard endpoints (renal insufficiency or ESRD) were reported. Segmental sclerosis was significantly associated with poor renal outcomes (8 studies with 1622 patients: hazard ratio, 1.59 [95\% confidence interval, 1.07-2.37], $\mathrm{P}=0.02$ ). Tubular atrophy/interstitial fibrosis and arteriosclerosis were also significantly associated with poor renal outcomes (7 studies with 1569 patients: 3.85 [2.16-6.87], $\mathrm{P}<0.000001$; and 5 studies with 1349 patients: 1.83 [1.17-2.86], $\mathrm{P}=0.008$ ). There were insufficient data to systematically assess the independent predictive value of $\mathrm{C} 3$ deposits and the stage and heterogeneity of electron dense deposits.

Conclusions: Significant associations of renal outcomes with segmental sclerosis, chronic tubule interstitial injury, and arteriosclerosis were only confirmed in two, five, and one of nine included studies, respectively. However, this meta-analysis indicated that each of these pathological features was significantly associated with progression of kidney disease. More methodologically sound and sufficiently powered prospective cohort studies with adequate number of patients and length of follow-up are still urgently needed to address the questions regarding prognostic utility of pathological features in adult IMN patients.

Keywords: Idiopathic membranous nephropathy; Pathology; Prognosis; End-stage renal disease; Meta-analysis

\section{Introduction}

Idiopathic Membranous Nephropathy (IMN) is the most common cause of primary nephrotic syndrome in adults [1,2]. IMN accounts for almost $20 \%$ of adult-onset nephrotic syndrome in North American or European populations [3]. The prevalence of IMN among Chinese patients with primary glomerulonephritis has increased from $7 \%$ in $1997-1999$ to $23 \%$ in 2009-2011 [4]. The diagnosis of IMN is made by renal biopsy, accompanied by the exclusion of secondary membranous nephropathy, mainly including systemic lupus erythematosus, chronic hepatitis B infection, malignancies, and drugs, as well as IgG4-related MN [5-14].

Indispensable pathological characteristics for the diagnosis of IMN are the presence of sub epithelial immune complex deposits and varied reactions of glomerular basement membranous material to the deposits. The rationale for the ultrastructure stages of IMN was first described by Ehrenreich and Churg in 1973 [15]. In 2004, Yoshimoto et al. proposed that electron dense deposits could be considered as homogeneous if they were all at any one stage or heterogeneous if distributed in more than one stage [16]. In 2006, Obana et al. proposed that the segmental and global status of IgG deposits along the capillary loops could be distinguished on the basis of immunofluorescence findings in pediatric IMN patients [17]. Segmental IMN is diagnosed by segmental granular IgG deposits along the capillary loops, whereas global IMN is diagnosed by global IgG deposits detected in the whole glomerulus. However, no new pathological classification by light microscopy has been proposed over the past few decades. This could be because overt hyper cellularity and crescent formation are uncommon in IMN [18]. Under light microscopy, glomeruli become segmentally and globally sclerotic with disease progression. Worsening tubular atrophy and interstitial fibrosis always parallel the progressive loss of renal function. Severity of vascular sclerosis might be associated with age, blood pressure, and renal function [19]. There is still uncertainty and long-term debate regarding the predictive value of these pathological features in adult IMN patients $[16,19-41]$.

In this meta-analysis, we focused on the independent predictive value of pathological features, including segmental sclerosis, tubular atrophy and interstitial fibrosis, arteriosclerosis, C3 deposits, and electron microscopy findings, in the development of renal insufficiency or the progression to End-Stage Renal Disease (ESRD).

\section{Methods}

\section{Data sources and searches}

We searched the PubMed database (from January 2000 to

*Corresponding author: Xiangmei Chen, Division of Nephrology, State Key Discipline of Kidney Diseases, State Key Laboratory of Kidney Diseases (2011DAV00088), Chinese People's Liberation Army (PLA) General Hospital (301 Hospital), Chinese PLA Medical Academy, 28 Fuxing Road, Haidian District, Beijing 100853, P. R. China, Tel: 861066935462; E-mail: xmchen301@126.com

Received October 25, 2013; Accepted November 18, 2013; Published November 22, 2013

Citation: Chen Y, Cai G, Chen X (2013) Meta-Analysis of Association between Pathological Characteristics and Renal Outcomes in Adult Idiopathic Membranous Nephropathy. J Nephrol Therapeutic S1: 002 doi:10.4172/2161-0959.S1-002

Copyright: (c) 2013 Chen Y, et al. This is an open-access article distributed under the terms of the Creative Commons Attribution License, which permits unrestricted use, distribution, and reproduction in any medium, provided the original author and source are credited. 
September 2013) to identify retrospective or perspective cohort studies of adult IMN patients in which at least one of the following pathological features was reported: segmental sclerosis, tubular atrophy and interstitial fibrosis, arteriosclerosis, C3 deposition, the stage or heterogeneity of electron dense deposits by electron microscopy. Reference lists from the identified articles were manually scanned to find any other relevant studies. Each study had a sample size of at least 50 patients. Renal outcomes in the included studies were the development of renal insufficiency or the progression to ESRD. Renal insufficiency was defined by the authors in each study.

\section{Study selection and data extraction}

The titles and abstracts, and full texts if necessary, were screened by two authors (Y.C. and G.C.). Study selection, data extraction, and data synthesis were independently performed by the same two authors using a standardized approach. Disagreements were resolved by consulting another author (X.C.). Standard information was separately extracted into a spreadsheet. The extracted data included patient baseline demographic and clinical features (country, sample size, duration of follow-up period, baseline estimated glomerular filtration rate (eGFR), proteinuria, percentage of patients with nephrotic-range proteinuria), pathological characteristics (percentages of patients with segmental sclerosis, tubular atrophy/interstitial fibrosis, arteriosclerosis, C3 deposits, stage III-IV, and heterogeneous deposits by electron microscopy), percentage of patients receiving immunosuppressive treatments, the number of pre-specified outcomes (renal insufficiency and ESRD), definition of pathological characteristics and pre-specified outcomes, and statistical methodology (univariate and multivariate analysis).

\section{Statistical analysis}

The Hazard Ratio (HR) and 95\% Confidence Interval (CI) were used as the summary statistic. A random-effects model, which is generally considered to be more conservative than a fixed-effect model, was used for data analysis. We used the Cochrane Q test to determine heterogeneity between studies and $\mathrm{I}^{2}$ statistics to further quantify the magnitude of heterogeneity. $\mathrm{P}<0.10$ was considered as an indicator for the existence of heterogeneity. To explore potential sources of heterogeneity, pre-specified subgroup analyses were performed to evaluate whether results were different by sample size $(<$ or $\geq 200)$, the length of the follow-up period ( $<$ or $\geq 7$ years), the choice of renal insufficiency or ESRD as the endpoint, the choice of univariate or multivariate analysis, baseline eGFR level $(<$ or $\geq 80 \mathrm{ml} / \mathrm{min} / 1.73$ $\left.\mathrm{m}^{2}\right)$, the percentage of patients with nephrotic-range proteinuria $(=$ or $<100 \%$ of enrolled patients), the percentage of patients receiving immunosuppressive treatments ( $<$ or $\geq 80 \%$ of enrolled patients), and region (North America/Europe or Asia). A two-sided $\mathrm{P}<0.05$ was considered as significant for all data analyses. All statistical analyses were performed using Review Manager (version 5.2) software.

\section{Results}

\section{Literature search results and study characteristics}

Finally, nine cohort studies were included in this review (Table 1). A total of 2080 patients with 252 hard endpoints (renal insufficiency or ESRD) were reported [16,19,31-33,35,38-40]. Seven studies reported the number of patients who developed renal insufficiency during follow-up, and eight studies reported the number of patients who reached ESRD during follow-up. Four cohorts were from Asian countries, and five were from North America and Europe. The median sample size was 105 (range, 53-949) and the median follow-up was 68 months (range, $48-116$ months). The mean or median eGFR was $\geq$ $80 \mathrm{ml} / \mathrm{min} / 1.73 \mathrm{~m}^{2}$ in five of nine studies. Three studies only enrolled IMN patients with nephrotic-range proteinuria. Four cohorts reported that more than $80 \%$ of enrolled patients received immunosuppressive treatments. Segmental sclerosis was reported in seven studies, with an incidence of 5-57\%. Chronic tubule interstitial injuries were reported in six studies, with an incidence of 9-65\%. Arteriosclerosis was reported in six studies, with an incidence of $38-77 \%$. C3 deposits were only reported in two studies, with an incidence of $68-88 \%$. The percentage of stage III or IV was reported in seven studies, with an incidence of $18-57 \%$. The percentage of heterogeneous electron dense deposits was reported in three studies, with an incidence of $43-52 \%$.

\section{Association of segmental sclerosis with renal outcomes}

Eight of nine included studies with 1622 patients were included in the meta-analysis of the association of segmental sclerosis with renal outcomes. Overall, segmental sclerosis was significantly associated with poor renal outcomes (HR 1.59, 95\% CI 1.07-2.37, $\mathrm{P}=0.02$ ), with significant heterogeneity $\left(\mathrm{I}^{2}=58 \%, \mathrm{P}=0.02\right)$ (Figure 1$)$. No significant subgroup differences were observed according to the sample size, the length of the follow-up period, the choice of renal insufficiency

\begin{tabular}{|c|c|c|c|c|c|c|c|c|c|c|c|c|c|c|c|}
\hline Study & Country & $\mathbf{N}$ & $\begin{array}{l}F / U \\
(\mathrm{mo})\end{array}$ & $\begin{array}{c}\text { eGFR } \\
(\mathrm{ml} / \mathrm{min})\end{array}$ & $\begin{array}{l}\text { Protein- } \\
\text { uria } \\
(\mathrm{g} / \mathrm{d})\end{array}$ & $\begin{array}{c}\text { Nephrotic } \\
(\%)\end{array}$ & $\begin{array}{c}\text { Immuno- } \\
\text { suppression } \\
(\%)\end{array}$ & $\begin{array}{l}\text { Segmental } \\
\text { Sclerosis } \\
(\%)\end{array}$ & $\begin{array}{c}\text { Tubular } \\
\text { atrophyl } \\
\text { Interstitial } \\
\\
\text { (>25\%) (\%) }\end{array}$ & $\begin{array}{l}\text { Arterio- } \\
\text { sclerosis } \\
(\%)\end{array}$ & $\begin{array}{c}\text { C3 } \\
\text { deposit } \\
(\%)\end{array}$ & $\begin{array}{c}\text { EM } \\
\text { stage } \geq 3 \\
(\%)\end{array}$ & $\begin{array}{c}\text { EM type } \\
\text { heterogeneous } \\
(\%)\end{array}$ & $\begin{array}{c}\text { Renal } \\
\text { failure } \\
(\%)\end{array}$ & $\begin{array}{c}\text { ESRD } \\
(\%)\end{array}$ \\
\hline Zuo 2013 & China & 217 & 74 & 110 & 3.9 & $139(64)$ & $121(56)$ & - & - & - & - & - & - & $24(12)^{G}$ & $10(5)$ \\
\hline $\begin{array}{l}\text { Sprangers } \\
2012\end{array}$ & USA & $132^{A}$ & 68 & 77 & 9.0 & $92(70)$ & $98(74)$ & $24(21)$ & $23(20)$ & $90(77)$ & - & $33(33)$ & - & $36(27)^{\mathrm{H}}$ & $9(7)$ \\
\hline Horvatic 2012 & Croatia & 60 & 48 & 75 & 7.7 & $56(93)$ & $51(85)$ & $34(57)$ & $-D$ & $33(55)$ & $53(88)$ & $26(43)$ & $31(52)$ & $12(20)^{\prime}$ & - \\
\hline Eriguchi 2009 & Japan & 103 & 102 & 72 & 6.9 & $103(100)$ & $103(100)$ & $28(27)$ & $31(30)^{\mathrm{E}}$ & $52(50)$ & - & $36(35)$ & - & $12(12)^{\mathrm{J}}$ & $4(4)$ \\
\hline Heeringa 2007 & Netherlands & 53 & 62 & 85 & 7.0 & $53(100)$ & $20(38)$ & $22(42)$ & $33(62)$ & - & - & $16(30)$ & - & $24(45)^{\prime}$ & $6(11)$ \\
\hline Troyanov 2006 & Canada & 389 & 58 & 76 & 4.7 & 348 (89) & $220(57)$ & $97(25)$ & $70(18)$ & $210(54)$ & $\begin{array}{l}264 \\
(68)\end{array}$ & $222(57)$ & $202(52)$ & - & $50(13)$ \\
\hline $\begin{array}{c}\text { Yoshimoto } \\
2004\end{array}$ & Japan & 105 & 116 & 96 & - & $75(71)$ & $88(84)$ & - & - & - & - & - & $45(43)$ & - & $12(11)$ \\
\hline Shiiki 2004 & Japan & $949^{B}$ & 83 & $90(10)^{c}$ & $>3.5$ & $949(100)$ & $788(83)$ & $29(5)$ & $54(9)^{F}$ & $222(38)$ & - & $111(18)$ & - & $79(8)^{\mathrm{K}}$ & $47(5)$ \\
\hline Dumoulin 2003 & France & 72 & 48 & 88 & 7.1 & $61(85)$ & $33(46)$ & $30(42)$ & $47(65)$ & $28(39)$ & - & $13(18)$ & - & $27(38)^{\mathrm{L}}$ & $18(25)$ \\
\hline
\end{tabular}

A: 117 of 132 patients (89\%) were available for light microscopic evaluation; B: 578 of 949 patients $(61 \%)$ were available for light microscopic evaluation and 610 of 949 $(64 \%)$ patients were available for electronic microscopic evaluation; C: 90 of 949 (10\%) patients had baseline serum creatinine $\geq 1.5 \mathrm{mg} / \mathrm{dl}$; $\mathrm{D}$ : the cut-off value was $18 \%$; E: the cut-off value was $10 \%$; F: the cut-off value was $20 \%$; G: eGFR $<60 \mathrm{ml} / \mathrm{min}$ per $1.73 \mathrm{~m}^{2} ; \mathrm{H}$ : doubling of serum creatinine; I: $\geq 50 \%$ increase of eGFR or death; J: serum creatinine $>1.5 \mathrm{mg} / \mathrm{dl}$ or $>50 \%$ increase from baseline value; $\mathrm{K}$ : serum creatinine $>3.0 \mathrm{mg} / \mathrm{dl}$; L: serum creatinine $>1.7 \mathrm{mg} / \mathrm{dl}$. 


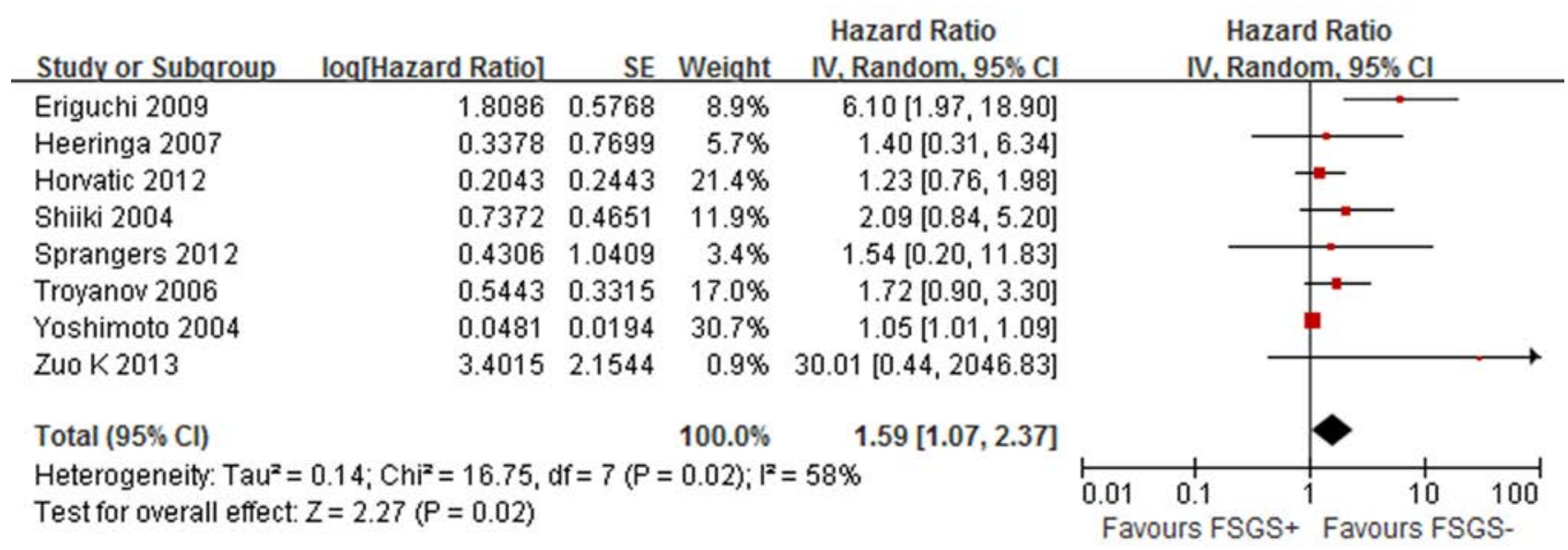

Figure 1: Meta-analysis of association of segmental sclerosis with renal outcomes (renal insufficiency or ESRD).

\begin{tabular}{|c|c|c|c|c|}
\hline \multicolumn{2}{|c|}{ Subgroups analysis of segmental sclerosis } & \multirow{3}{*}{$\begin{array}{c}\text { No. of trials } \\
3 \\
5\end{array}$} & \multirow{3}{*}{$\begin{array}{c}\text { Hazard ratio }(95 \% \mathrm{Cl}) \\
1.92(1.14,3.25) \\
1.43(0.89,2.31)\end{array}$} & \multirow{3}{*}{$\begin{array}{c}\text { P-subgroup difference } \\
0.42\end{array}$} \\
\hline \multirow{2}{*}{ Sample size } & $>200$ & & & \\
\hline & $<200$ & & & \\
\hline \multirow{2}{*}{ Follow-up } & $>7$ years & 4 & $2.43(0.87,6.73)$ & \multirow{2}{*}{0.31} \\
\hline & $<7$ years & 4 & $1.39(0.96,2.00)$ & \\
\hline \multirow{2}{*}{ Endpoint } & \multirow{2}{*}{$\begin{array}{c}\text { ESRD } \\
\text { Renal failure }\end{array}$} & 5 & $1.21(0.87,1.68)$ & \multirow{2}{*}{0.20} \\
\hline & & 3 & $2.22(0.93,5.35)$ & \\
\hline \multirow{2}{*}{ Adjustment } & \multirow{2}{*}{$\begin{array}{l}\text { Univariate } \\
\text { Multivariate }\end{array}$} & 4 & $2.70(1.12,6.48)$ & \multirow{2}{*}{0.04} \\
\hline & & 4 & $1.05(1.01,1.09)$ & \\
\hline \multirow{2}{*}{ Baseline eGFR } & \multirow{2}{*}{$\begin{array}{l}<80 \mathrm{ml} / \mathrm{min} \text { per } 1.73 \mathrm{~m}^{2} \\
>80 \mathrm{ml} / \mathrm{min} \text { per } 1.73 \mathrm{~m}^{2}\end{array}$} & 4 & $1.91(1.01,3.62)$ & \multirow{2}{*}{0.43} \\
\hline & & 4 & $1.36(0.77,2.40)$ & \\
\hline \multirow{2}{*}{ Percentage of nephrotic syndrome } & $100 \%$ & 3 & $2.75(1.22,6.20)$ & \multirow{2}{*}{0.05} \\
\hline & $<100 \%$ & 5 & $1.16(0.91,1.48)$ & \\
\hline \multirow{2}{*}{ Percentage of immunosuppression } & $>80 \%$ & 5 & $1.56(0.96,2.53)$ & \multirow{2}{*}{0.75} \\
\hline & $<80 \%$ & 3 & $1.77(0.98,3.19)$ & \\
\hline \multirow{2}{*}{ Country } & North American/Europe & 4 & $1.39(0.96,2.00)$ & \multirow{2}{*}{0.31} \\
\hline & Asia & 4 & $2.43(0.87,6.73)$ & \\
\hline
\end{tabular}

Table 2: Subgroup analysis of the association of segmental sclerosis with renal outcomes.

or ESRD as endpoint, baseline eGFR level, the percentage of patients receiving immunosuppressive treatments, and country (Table 2). In subgroup analysis, multivariate analysis yielded a more conservative estimate of the association of segmental sclerosis with renal outcomes than univariate analysis (HR 1.05, 95\% CI 1.01-1.09 versus HR 2.70, 95\% CI 1.12-6.48; subgroup difference: $\mathrm{P}=0.04$ ). There was a significant subgroup difference between studies that only enrolled IMN patients with nephrotic-range proteinuria and studies that included patients with sub-nephrotic range and nephrotic-range proteinuria (subgroup difference: $\mathrm{P}=0.05$ ). Segmental sclerosis was significantly associated with poor renal outcomes in three studies that only enrolled patients with nephrotic-range proteinuria (HR 2.75, 95\% CI 1.22-6.20). However, there was no such significant association in four studies that enrolled patients with sub-nephrotic range and nephrotic-range proteinuria (HR 1.16, 95\% CI 0.91-1.48).

\section{Association of tubular atrophy/interstitial fibrosis with renal outcomes}

Seven of nine included studies with 1569 patients were included in the meta-analysis of the association of tubular atrophy and interstitial fibrosis with renal outcomes. Overall, tubular atrophy and interstitial fibrosis were significantly associated with poor renal outcomes (HR $3.85,95 \%$ CI 2.16-6.87, $\mathrm{P}<0.000001$ ), without significant heterogeneity
$\left(\mathrm{I}^{2}=40 \%, \mathrm{P}=0.13\right)$ (Figure 2). No significant subgroup differences were observed according to the sample size, the length of the follow-up period, the choice of univariate or multivariate analysis, baseline eGFR level, the percentage of patients with nephrotic-range proteinuria, and country (Table 3). Subgroup analysis showed that the association of tubular atrophy and interstitial fibrosis with renal insufficiency was greater than that with ESRD (HR 6.91, 95\% CI 2.87-16.62 versus HR 2.47, 95\% CI 1.41-4.34; subgroup difference: $\mathrm{P}=0.05$ ). In four studies that gave immunosuppressive treatments to more than $80 \%$ of enrolled patients, the HR of the association with renal outcomes was 5.99 (95\% CI 3.29-10.89) compared with 2.21 (95\% CI 1.22-4.00) in another three studies that gave immunosuppressive treatments to less than $80 \%$ of enrolled patients (subgroup difference: $\mathrm{P}=0.02$ ). A well-known fact is that the more severe the disease (not reaching ESRD), the more chance of receiving immunosuppressive treatments. The decision to use immunosuppressive treatments might be an indicator of the severity of the disease. Therefore, subgroup analysis indicated that the association of tubular atrophy and interstitial fibrosis with renal outcomes was greater in patients with more severe disease.

\section{Association of arteriosclerosis with renal outcomes}

Five of nine included studies with 1349 patients were included in the meta-analysis of the association of arteriosclerosis with renal 


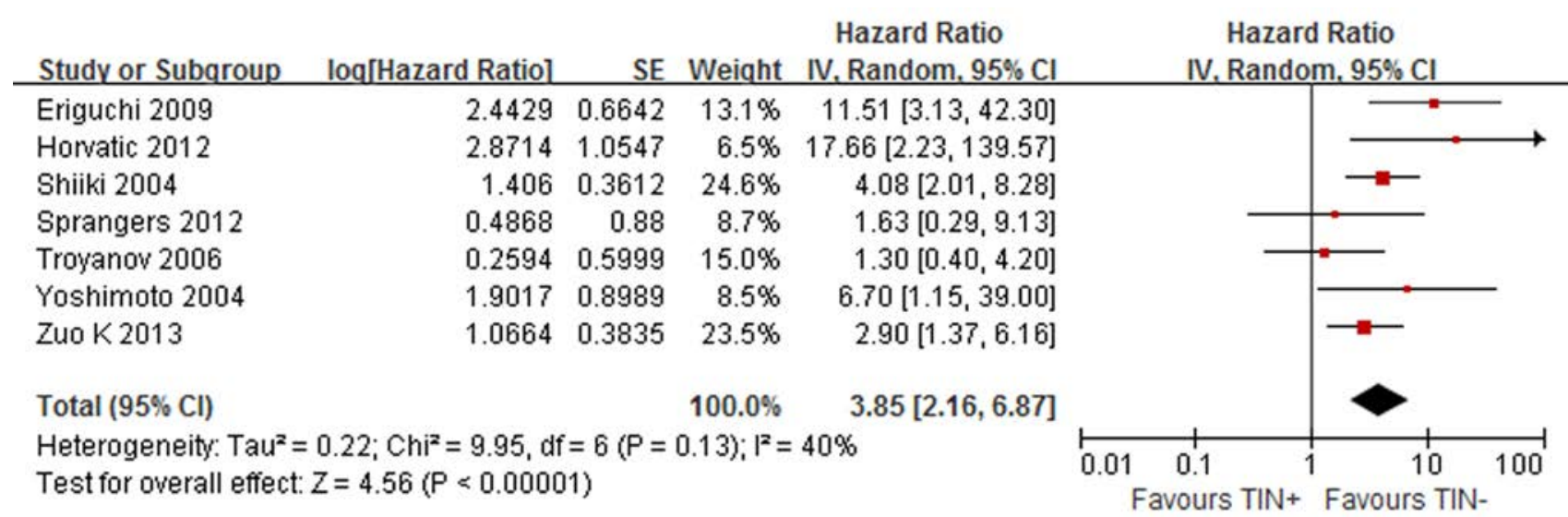

Figure 2: Meta-analysis of association of chronic tubulointerstitial injury with renal outcomes (renal insufficiency or ESRD).

\begin{tabular}{|c|c|c|c|c|}
\hline \multicolumn{2}{|c|}{ Subgroups analysis of chronic tubulointerstitial injuries } & \multirow{2}{*}{$\begin{array}{c}\text { No. of trials } \\
3\end{array}$} & \multirow{2}{*}{$\begin{array}{c}\text { Hazard ratio }(95 \% \mathrm{CI}) \\
2.87(1.64,5.02)\end{array}$} & \multirow{3}{*}{$\begin{array}{c}\text { P-subgroup difference } \\
0.13\end{array}$} \\
\hline \multirow{2}{*}{ Sample size } & $>200$ & & & \\
\hline & $<200$ & 4 & $6.88(2.59,18.25)$ & \\
\hline \multirow{2}{*}{ Follow-up } & $>7$ years & 4 & $4.36(2.59,7.32)$ & \multirow{2}{*}{0.57} \\
\hline & $<7$ years & 3 & $2.79(0.65,11.92)$ & \\
\hline \multirow{2}{*}{ Endpoint } & \multirow{2}{*}{$\begin{array}{c}\text { ESRD } \\
\text { Renal failure }\end{array}$} & 4 & $2.47(1.41,4.34)$ & \multirow{2}{*}{0.05} \\
\hline & & 3 & $6.91(2.87,16.62)$ & \\
\hline \multirow{2}{*}{ Adjustment } & \multirow{2}{*}{$\begin{array}{l}\text { Univariate } \\
\text { Multivariate }\end{array}$} & 2 & $4.71(0.70,31.81)$ & \multirow{2}{*}{0.77} \\
\hline & & 5 & $1.05(1.01,1.09)$ & \\
\hline \multirow{2}{*}{ Baseline eGFR } & \multirow{2}{*}{$\begin{array}{l}<80 \mathrm{ml} / \mathrm{min} \text { per } 1.73 \mathrm{~m}^{2} \\
>80 \mathrm{ml} / \mathrm{min} \text { per } 1.73 \mathrm{~m}^{2}\end{array}$} & 4 & $4.20(1.12,15.68)$ & \multirow{2}{*}{0.85} \\
\hline & & 3 & $3.66(2.23,6.01)$ & \\
\hline \multirow{2}{*}{ Percentage of nephrotic syndrome } & $100 \%$ & 2 & $5.90(2.23,15.60)$ & \multirow{2}{*}{0.28} \\
\hline & $<100 \%$ & 5 & $2.99(1.42,6.29)$ & \\
\hline \multirow{2}{*}{ Percentage of immunosuppression } & $>80 \%$ & 4 & $5.99(3.29,10.89)$ & \multirow{2}{*}{0.02} \\
\hline & $<80 \%$ & 3 & $2.21(1.22,4.00)$ & \\
\hline \multirow{2}{*}{ Country } & North American/Europe & 3 & $2.79(0.65,11.92)$ & \multirow{2}{*}{0.57} \\
\hline & Asia & 4 & $4.36(2.59,7.32)$ & \\
\hline
\end{tabular}

Table 3: Subgroup analysis of the association of chronic tubulointerstitial injuries with renal outcomes.

outcomes. Overall, arteriosclerosis was significantly associated with poor renal outcomes (HR 1.83, 95\% CI 1.17-2.86, $\mathrm{P}=0.008$ ), without significant heterogeneity $\left(\mathrm{I}^{2}=0 \%, \mathrm{P}=0.49\right)$ (Figure 3 ). No significant subgroup differences were observed according to the sample size, the length of the follow-up period, the choice of renal insufficiency or ESRD as an endpoint, the choice of univariate or multivariate analysis, baseline eGFR level, the percentage of patients with nephrotic-range proteinuria, the percentage of patients receiving immunosuppressive treatments, and country (Table 4).

\section{Association of C3 deposits with renal outcomes}

Only two studies analyzed the association between $\mathrm{C} 3$ deposits and renal outcomes [19,32]. Both studies confirmed that C3 deposits were not an independent predictor of renal outcomes. There were insufficient data to systematically assess the independent predictive value of C3 deposits in adult IMN patients.

\section{Association of ultrastructure features with renal outcomes}

Seven of nine studies reported ultrastructure stages under electron microscopy. The reported median percentage of patients with stage III or IV was 33\% (range, 18-57\%). Only three of nine studies classified electron dense deposits as homogeneous or heterogeneous on the basis of electron microscopy findings. The percentage of patients with heterogeneous deposits was $43-52 \%$. Only one study demonstrated that heterogeneous deposits were an indicator of poor prognosis of IMN patients [16]. All the remaining studies did not find that the stage and heterogeneity of deposits were significantly correlated with renal outcomes. There were insufficient data to systematically assess the independent predictive value of ultrastructure stage and heterogeneity of electron dense deposits in IMN patients.

\section{Discussion}

Dumoulin et al. found that segmental sclerosis was superimposed in 30 of $72 \mathrm{IMN}$ patients [35]. Multiple regression analysis confirmed that segmental sclerosis was independently associated with progression to renal insufficiency. Yoshimoto et al. retrospectively analyzed the prognosis of 105 Japanese patients with IMN who were followed up for at least 5 years or until ESRD or death [16]. Segmental sclerosis was an independent indicator of developing ESRD (HR 1.04, 95\% CI 1.011.09). In contrast, one study showed that segmental sclerosis could not independently predict the risk of development of renal insufficiency in 60 Croatian IMN patients [32]. Similarly, three studies failed to demonstrate that segmental sclerosis could predict the progression to ESRD by univariate analysis [19,31,40]. Although two studies found that segmental sclerosis was associated with renal insufficiency by univariate analysis, this association between segmental sclerosis 


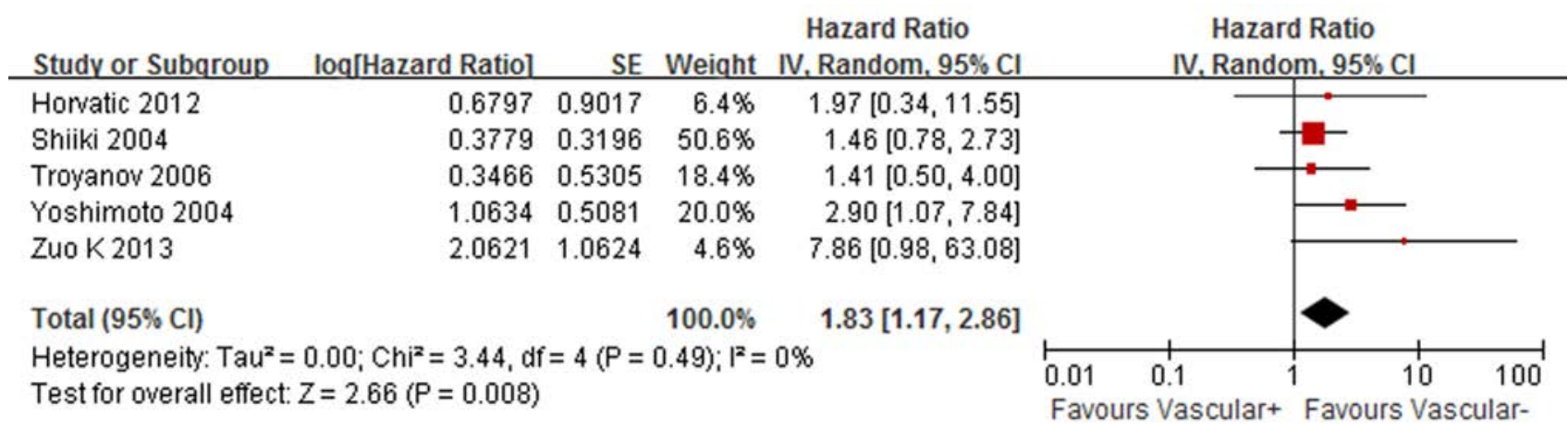

Figure 3: Meta-analysis of association of arteriosclerosis with renal outcomes (renal insufficiency or ESRD).

\begin{tabular}{|c|c|c|c|c|}
\hline \multicolumn{2}{|c|}{ Subgroups analysis of arteriosclerosis } & No. of trials & Hazard ratio $(95 \% \mathrm{Cl})$ & P-subgroup difference \\
\hline \multirow{2}{*}{ Sample size } & $>200$ & 3 & $1.67(0.90,3.09)$ & \multirow{2}{*}{0.40} \\
\hline & $<200$ & 2 & $2.64(1.11,6.29)$ & \\
\hline \multirow{2}{*}{ Follow-up } & $>7$ years & 1 & $2.90(1.07,7.84)$ & \multirow{2}{*}{0.31} \\
\hline & $<7$ years & 4 & $1.63(0.99,2.69)$ & \\
\hline \multirow{2}{*}{ Endpoint } & \multirow{2}{*}{$\begin{array}{c}\text { ESRD } \\
\text { Renal failure }\end{array}$} & 3 & $2.43(1.13,5.20)$ & \multirow{2}{*}{0.34} \\
\hline & & 2 & $1.51(0.84,2.72)$ & \\
\hline \multirow{2}{*}{ Adjustment } & \multirow{2}{*}{$\begin{array}{l}\text { Univariate } \\
\text { Multivariate }\end{array}$} & 0 & - & \multirow{2}{*}{-} \\
\hline & & 5 & $1.83(1.17,2.86)$ & \\
\hline \multirow{2}{*}{ Baseline eGFR } & \multirow{2}{*}{$\begin{array}{l}<80 \mathrm{ml} / \mathrm{min} \text { per } 1.73 \mathrm{~m}^{2} \\
>80 \mathrm{ml} / \mathrm{min} \text { per } 1.73 \mathrm{~m}^{2}\end{array}$} & 2 & $1.54(0.63,3.78)$ & \multirow{2}{*}{0.53} \\
\hline & & 3 & $2.23(1.06,4.73)$ & \\
\hline \multirow{2}{*}{ Percentage of nephrotic syndrome } & $100 \%$ & 1 & $1.46(0.78,2.73)$ & \multirow{2}{*}{0.31} \\
\hline & $<100 \%$ & 4 & $2.32(1.23,4.37)$ & \\
\hline \multirow{2}{*}{ Percentage of immunosuppression } & $>80 \%$ & 3 & $1.79(1.08,2.97)$ & \multirow{2}{*}{0.66} \\
\hline & $<80 \%$ & 2 & $2.60(0.52,13.03)$ & \\
\hline \multirow{2}{*}{ Country } & North American/Europe & 2 & $1.54(0.63,3.78)$ & \multirow{2}{*}{0.53} \\
\hline & Asia & 3 & $2.23(1.06,4.73)$ & \\
\hline
\end{tabular}

Table 4: Subgroup analysis of the association of arteriosclerosis with renal outcomes.

and renal insufficiency disappeared after adjustment for clinical and other pathological parameters [33,39]. Sprangers et al. described 132 IMN patients who were followed for a mean period of 68 months and analyzed the pathological features that predicted renal outcomes [38]. A significant association of segmental sclerosis with a higher risk of progression to ESRD could only be identified by univariate analysis, but not multivariate analysis. Although at least nine cohort studies attempted to evaluate a significant association between segmental sclerosis and renal outcomes, not every study enrolled a sufficient sample size to examine this association. The number of hard endpoints was also limited in each cohort. The median numbers of patients reaching renal insufficiency and ESRD were 24 and 11, respectively. Systematic review and meta-analysis increased the sample size and the number of hard endpoints by pooling of the data from each individual study. One preliminary meta-analysis of six studies demonstrated that segmental sclerosis was associated with a lower remission rate [40]. For the first time, we examined the association between segmental sclerosis and renal outcomes by using a meta-analysis strategy. This association could be quantitatively summarized in eight of nine studies with 1622 patients. A total of 249 (15\%) patients reached renal insufficiency or developed ESRD during follow-up. This meta-analysis demonstrated that segmental sclerosis was significantly associated with poor renal outcomes.

Four studies consistently reported that tubular atrophy and interstitial fibrosis were an independent predictor of renal insufficiency $[32,33]$ or ESRD [16,31]. Eriguchi et al. found that interstitial fibrosis was associated with renal sufficiency by univariate analysis [39]. However, multivariate analysis failed to confirm the independently predictive value of interstitial fibrosis in 103 consecutive Japanese nephrotic IMN patients. Troyanov et al. examined the independent value of pathological features at the time of biopsy in predicting renal outcomes in 389 IMN patients [19]. Similarly, chronic tubule interstitial disease did predict a lower renal survival in univariate analysis. However, this was not independent of baseline renal function, age, and blood pressure at biopsy. Three studies did not examine the predictive value of tubular atrophy or interstitial fibrosis because of the strong association with segmental sclerosis $[35,40]$ or baseline renal function [38]. In the present meta-analysis, the association of tubular atrophy and interstitial fibrosis with renal outcomes was quantitatively summarized in seven of nine included studies with 1569 patients. A total of 225 (14\%) patients reached renal insufficiency or developed ESRD during follow-up. This meta-analysis demonstrated that tubular atrophy and interstitial fibrosis were significantly associated with poor renal outcomes.

Only one study demonstrated that arteriosclerosis was an independent indicator of renal outcomes [16]. Five studies failed to identify a significant association of arteriosclerosis with renal outcomes in multivariate analysis [19,31-33,35]. The remaining three studies did not examine the association of arteriosclerosis with renal outcomes [38-40]. The association of arteriosclerosis with renal outcomes was quantitatively summarized in five of nine included studies with 1349 patients. A total of 177 (13\%) patients reached renal insufficiency or 
developed ESRD during follow-up. This meta-analysis demonstrated that arteriosclerosis was significantly associated with poor renal outcomes.

\section{Conclusions}

This meta-analysis shows that segmental sclerosis, chronic tubule interstitial injury, and arteriosclerosis are significantly associated with progression of kidney disease. However, there were discrepancies between the results from the meta-analysis and those from individual studies. Significant associations of renal outcomes with segmental sclerosis, chronic tubule interstitial injury, and arteriosclerosis were only confirmed in two, five, and one of nine included studies, respectively. Meta-analysis could overcome the limitation that not every individual study had a sufficient number of enrolled patients and adequate occurrence of hard endpoints. However, several factors decreased the quality of the evidence. Selective outcome reporting bias was the major limitation. None of the included nine studies reported all of the HRs from univariate and multivariate analyses of the association of each pathological feature with the development of renal insufficiency and progression to ESRD. The definitions of pathological features and renal insufficiency varied among included studies and could be partially responsible for the heterogeneity of the summarized results. The results of our meta-analysis should be interpreted with caution because of these inherent limitations. More methodologically sound and sufficiently powered prospective cohort studies with adequate number of patients and length of follow-up are still urgently needed to address the questions regarding prognostic utility of pathological features in adult IMN patients.

\section{Sources of Support}

This work was partially supported by the National Clinical Research Center for Kidney Disease (No. 2013BAI09B05). The funder had no role in study design, data collection and analysis, decision to publish, or preparation of the manuscript.

\section{Conflict of Interest}

None.

\section{References}

1. McQuarrie EP, Mackinnon B, Stewart GA, Geddes CC (2010) Scottish Renal Biopsy R. Membranous nephropathy remains the commonest primary cause of nephrotic syndrome in a northern European Caucasian population. Nephrol Dial Transplant 25: 1009-1010.

2. Xie J, Chen N (2013) Primary glomerulonephritis in mainland China: an overview. Contrib Nephrol 181: 1-11.

3. Glassock RJ (2010) The pathogenesis of idiopathic membranous nephropathy: a 50-year odyssey. Am J Kidney Dis 56: 157-167.

4. Pan X, Xu J, Ren H, Zhang W, Xu Y, et al. (2013) Changing spectrum of biopsyproven primary glomerular diseases over the past 15 years: a single-center study in China. Contrib Nephrol 181: 22-30.

5. Hofstra JM, Fervenza FC, Wetzels JF (2013) Treatment of idiopathic membranous nephropathy. Nat Rev Nephrol 9: 443-458.

6. Ponticelli C, Glassock RJ (2013) Glomerular Diseases: Membranous Nephropathy--A Modern View. Clin J Am Soc Nephrol.

7. Glassock RJ (2013) Pathogenesis of membranous nephropathy: a new paradigm in evolution. Contrib Nephrol 181: 131-142.

8. Saeki T, Kawano M (2013) IgG4-related kidney disease. Kidney Int.

9. Nawaz FA, Larsen CP, Troxell ML (2013) Membranous Nephropathy and Nonsteroidal Anti-inflammatory Agents. Am J Kidney Dis 62: 1012-1017.

10. Saeki T, Kawano M, Mizushima I, Yamamoto M, Wada Y, et al. (2013) The clinical course of patients with IgG4-related kidney disease. Kidney Int 84: 826833.

11. Stone JH (2013) IgG4: a tantalizing link between causes of membranous glomerulonephritis and systemic disease. Kidney Int 83: 348-350.

12. Filippone EJ (2013) Idiopathic membranous nephropathy and IgG4: an interesting relationship. Clin Nephrol.

13. Alexander MP, Larsen CP, Gibson IW, Nasr SH, Sethi S, et al. (2013) Membranous glomerulonephritis is a manifestation of IgG4-related disease. Kidney Int 83: 455-462

14. Stone JH, Zen Y, Deshpande V (2012) IgG4-related disease. N Engl J Med 366: 539-551.

15. Churg J, Ehrenreich T (1973) Membranous nephropathy. Perspect Nephrol Hypertens 1 Pt 1: 443-448.

16. Yoshimoto K, Yokoyama H, Wada T, Furuichi K, Sakai N, et al. (2004) Pathologic findings of initial biopsies reflect the outcomes of membranous nephropathy. Kidney Int 65: 148-153.

17. Obana M, Nakanishi K, Sako M, Yata N, Nozu K, et al. (2006) Segmenta membranous glomerulonephritis in children: comparison with global membranous glomerulonephritis. Clin J Am Soc Nephrol 1: 723-729.

18. Basford AW, Lewis J, Dwyer JP, Fogo AB (2011) Membranous nephropathy with crescents. J Am Soc Nephrol 22: 1804-1808.

19. Troyanov S, Roasio L, Pandes M, Herzenberg AM, Cattran DC (2006) Renal pathology in idiopathic membranous nephropathy: a new perspective. Kidney Int 69: 1641-1648.

20. Gluck MC, Gallo G, Lowenstein J, Baldwin DS (1973) Membranous glomerulonephritis. Evolution of clinical and pathologic features. Ann Intern Med 78: 1-12.

21. Noel LH, Zanetti M, Droz D, Barbanel C (1979) Long-term prognosis of idiopathic membranous glomerulonephritis. Study of 116 untreated patients. Am J Med 66: 82-90.

22. Ramzy MH, Cameron JS, Turner DR, Neild GH, Ogg CS, et al. (1981) The longterm outcome of idiopathic membranous nephropathy. Clin Nephrol 16: 13-19.

23. Törnroth T, Honkanen E, Pettersson E (1987) The evolution of membranous glomerulonephritis reconsidered: new insights from a study on relapsing disease. Clin Nephrol 28: 107-117.

24. Zucchelli P, Ponticelli C, Cagnoli L, Passerini P (1987) Long-term outcome of idiopathic membranous nephropathy with nephrotic syndrome. Nephrol Dial Transplant 2: 73-78.

25. Ponticelli C, Zucchelli P, Passerini P, Cagnoli L, Cesana B, et al. (1989) A randomized trial of methylprednisolone and chlorambucil in idiopathic membranous nephropathy. N Engl J Med 320: 8-13.

26. Wehrmann M, Bohle A, Bogenschutz O, Eissele R, Freislederer A, et al. (1989) Long-term prognosis of chronic idiopathic membranous glomerulonephritis. An analysis of 334 cases with particular regard to tubulo-interstitial changes. Clin Nephrol 31: 67-76.

27. Honkanen E, Törnroth T, Grönhagen-Riska C (1992) Natural history, clinical course and morphological evolution of membranous nephropathy. Nephrol Dial Transplant 7 Suppl 1: 35-41.

28. Tóth T, Takebayashi S (1994) Factors contributing to the outcome in 100 adult patients with idiopathic membranous glomerulonephritis. Int Urol Nephrol 26: 93-106.

29. Marx BE, Marx M (1999) Prediction in idiopathic membranous nephropathy Kidney Int 56: 666-673.

30. Wu Q, Jinde K, Nishina M, Tanabe R, Endoh M, et al. (2001) Analysis of prognostic predictors in idiopathic membranous nephropathy. Am J Kidney Dis 37: $380-387$

31. Zuo K, Wu Y, Li SJ, Xu F, Zeng CH, et al. (2013) Long-term outcome and prognostic factors of idiopathic membranous nephropathy in the Chinese population. Clin Nephrol 79: 445-453.

32. Horvatic I, Ljubanovic DG, Bulimbasic S, Knotek M, Prkacin I, et al. (2012) Prognostic significance of glomerular and tubulointerstitial morphometry in idiopathic membranous nephropathy. Pathol Res Pract 208: 662-667.

33. Shiiki H, Saito T, Nishitani Y, Mitarai T, Yorioka N, et al. (2004) Prognosis and 
Citation: Chen Y, Cai G, Chen X (2013) Meta-Analysis of Association between Pathological Characteristics and Renal Outcomes in Adult Idiopathic Membranous Nephropathy. J Nephrol Therapeutic S1: 002 doi:10.4172/2161-0959.S1-002

risk factors for idiopathic membranous nephropathy with nephrotic syndrome in Japan. Kidney Int 65: 1400-1407.

34. Paraskevakou H, Kavantzas N, Pavlopoulos PM, Voudiklari S, Zerefos N, et al. (2000) Membranous glomerulonephritis: a morphometric study. Pathol Res Pract 196: 141-144.

35. Dumoulin A, Hill GS, Montseny JJ, Meyrier A (2003) Clinical and morphological prognostic factors in membranous nephropathy: significance of focal segmental glomerulosclerosis. Am J Kidney Dis 41: 38-48.

36. Lee HS, Koh HI (1993) Nature of progressive glomerulosclerosis in human membranous nephropathy. Clin Nephrol 39: 7-16.

37. Wakai S, Magil AB (1992) Focal glomerulosclerosis in idiopathic membranous glomerulonephritis. Kidney Int 41: 428-434.

38. Sprangers B, Bomback AS, Cohen SD, Radhakrishnan J, Valeri A, et al. (2012)
Idiopathic membranous nephropathy: clinical and histologic prognostic features and treatment patterns over time at a tertiary referral center. Am J Nephrol 36: 78-89.

39. Eriguchi M, Oka H, Mizobuchi T, Kamimura T, Sugawara K, et al. (2009) Longterm outcomes of idiopathic membranous nephropathy in Japanese patients treated with low-dose cyclophosphamide and prednisolone. Nephrol Dial Transplant 24: 3082-3088.

40. Heeringa SF, Branten AJ, Deegens JK, Steenbergen E, Wetzels JF (2007) Focal segmental glomerulosclerosis is not a sufficient predictor of renal outcome in patients with membranous nephropathy. Nephrol Dial Transplant 22: $2201-2207$.

41. Doi T, Kanatsu K, Nagai H, Suehiro F, Kuwahara T, et al. (1984) Demonstration of C3d deposits in membranous nephropathy. Nephron 37: 232-235.

This article was originally published in a special issue, Kidney Diseases \& Treatment handled by Editor(s). Dr. Qian Qi, Mayo Clinic College of Medicine, United States 